\title{
Trends and patterns in communication research on Asia A review of publications in top SSCI journals, 1995-2014
}

\author{
Xun Liu and Ran Wei
}

MedieKultur 2017, 62, 6-17

Published by SMID | Society of Media researchers In Denmark | www.smid.dk The online version of this text can be found open access at www.mediekultur.dk

\begin{abstract}
Communication research in Asia has enjoyed rapid growth in the $20^{\text {th }}$ century thanks to Asia's economic boom, rapid growth in communication technologies and expanded university faculties. To explore the extent to which the rise of Asian communication research has continued in the $21^{\text {st }}$ century, a total of 558 publications on Asian communication research in 14 top-ranked SSCI communication journals from 1995 to 2014 were analyzed. Results indicate a rise in Asian communication research in the $21^{\text {st }}$ century. However, the results also suggest patterns of unevenness in terms of publishing year, journals, region, research topics and methodology. Asian communication research was dominated by East Asia, which, in turn, was dominated by China, South Korea and Japan. In terms of research areas by topic, Asian communication scholarship focused on a few areas, including media effects, political communication, communication technology, and health communication. In terms of research methodologies, the quantitative approach was found to be dominant in the publications - more than twice that of qualitative research.
\end{abstract}




\section{Introduction}

As the world's largest continent, Asia is the home of 54 countries in which 4.4 billion people (60\% of the world population) live. It is also the most dynamic part of the global economy in terms of economic development and growth in trade (International Monetary Fund, 2016). Not surprisingly, the $21^{\text {st }}$ century has been called "the Asian Century" by Eastern and Western academics. Asia has been the engine of global growth in the past 15 years and is the site of several of the longest modern economic booms in the 20th century, including the Japanese economic miracle, South Korea's miracle of the Han River, and the threedecade economic boom in China. In 2016, the economic growth in Asia is expected to remain strong at 5.3 percent per year, accounting for two-thirds of global growth (IMF, 2016). Besides the economic giants of China, India and Japan, countries such as the Philippines, Vietnam and Indonesia have shown strong growth prospects. The Philippines and Vietnam are expected to grow more than 6\% in 2016 and Indonesia by 5.1\% in 2016 (World Bank, 2016).

One of the largest growth sectors is communication technology. New media and communication technology have gained momentum in Asia due to the rise of the middle class. Asia contains the world's most technologically innovative countries. South Korea, for example, has the fastest and most widespread broadband Internet in the world. Japan, Taiwan and China lead in communication technology hardware design and production. More importantly, the growth in the Internet and mobile telephone industry in Asia is unparalleled. As of June 2016, Asia has 17.2 billion Internet users, 38.2 billion mobile phone users and 17.5 billion active mobile broadband subscribers (ITU, 2016). Asia also accounts for $52.2 \%$ of global social media users (Go-global, 2016).

Communication research has enjoyed rapid growth in Asia in the past twenty years (So, 2010) thanks to Asia's economic boom, rapid growth in communication technologies and expanded university faculties. There was a surge of outlets that publish communication scholarship to the global audience. There are at least seven English-language journals that are devoted to communication research on Asia and in Asia, including Asian Journal of Communication, Asian Communication Research, Journal of Asian Pacific Communication, the Keio Communication Review, the Chinese Journal of Communication, Media Asia, and Communication and the Public.

The increasing importance of Asia as a region to the global economy and the increase of communication research on Asia provide an opportunity to review the state of communication scholarship and explore patterns of research and scholarly attention paid to various Asian countries. To be specific, the present study seeks to identify trends and patterns of communication research on Asia by reviewing research published in top communication journals from 1995 to 2014.

There are a number of disciplinary reviews of communication research on Asia in the literature. However, previous reviews of communication research on Asia tended to focus 
on specific areas of communication studies, such as international communication (Chitty, 2010), mobile media (Donner, 2008), health communication (Lwin \& Salmon, 2015), intercultural communication (Kim, 2010; Chen, 2006), and new media (Lim \& Goggin, 2010; Lo \& Wei, 2010; Wei, 2009). A comprehensive review of Asian communication scholarship is lacking. Considering the rapid changes in the scholarly landscape in Asia, it is an opportune time to review and reflect on the overall patterns and general trends of communication research on Asia. Therefore, the findings of the present study will contribute to the understanding of the current state of communication research on Asia from which the directions for future research will be identified.

\section{A review of Asian communication research in publications}

A number of past studies have examined the patterns and trends of communication in Asia from different perspectives or methodologies. So (2010) conducted a citation analysis of 666 publications on Asian communication research in $23 \mathrm{SSCl}$ journals from 1990 to 2009. His analysis found that the scholarly attention on Asia in these SSCl journals had more than doubled with 99 articles from 1990 to 1994 to 228 articles from 2005 to 2009. He characterized the growth as "the rise of Asian communication research" (p. 230).

An earlier study by Ha and Pratt (2000) on Greater China reported similar patterns. Their study found a sharp increase in the number of published articles on China between 1979 and 1998: from an average of 4.7 per year during the period of 1979-1988 to 35 per year during the period of 1989-1998.

Lo and Wei (2010) reviewed 34 articles in 11 major communication journals on new media and political communication about Asia during 1988 to 2008. According to their findings, 70.6\% of the publications appeared in the second 10-year period (1999-2008), while only $29.4 \%$ were published during $1988-1998$. As the scholarship on communication with respect to Asia continues to accumulate in the $21^{\text {st }}$ century, the first research question was raised to track the momentum in communication research about Asia:

RQ1: To what extent did Asian communication research rise from 1995 to 2014? What is the trend of published articles concerning Asian communication research over the past 20 years? What is the number of published articles by journals and years?

Furthermore, past studies reviewed the Asian countries that have been studied in published articles. Lim and Goggin (2014) noticed a significant gap with respect to the countries that were being studied in the literature of communication research on Asia. They found that, although the research on Asia is on the rise generally, the rise is uneven. A significant number of Asian countries were underrepresented in the published articles in communication journals because of underdeveloped and under-resourced universities and insufficient opportunities for faculty development in those countries. Other studies confirmed the 
gap. For example, Bryant and Yang (2004) examined publications on Asian communication in nine major communication journals between 1998 and 2002. They found that the countries that received the most attention were few; they were, respectively, China, Japan, and India, followed by Hong Kong, Taiwan, and South Korea.

In addition, So's citation analysis (2010) found that most publications focused on China (168 articles in all), Japan (totaling 111 articles), and South Korea (84 articles in total). As a result, the publications on these three East Asian countries made up more than half of all published articles (54.5\%). Kim's (2010) review of intercultural communication in Asia confirmed this uneven pattern. He reported that China, Singapore, Taiwan, Korea, Japan and India dominated Asian intercultural communication research. By comparison, other Asian countries were invisible.

To explore whether the gap still exists in the new century, the second research question was developed:

RQ2: Which region received the most scholarly attention in Asia from 1995 to 2014? And which Asian country(ies) received the most scholarly attention over the past twenty years?

In addition to an analysis of the regions and countries that were studied most in published Asian communication research, past reviews also examined the distribution of research by topical areas as another important aspect of Asian communication research. Results reported in several review studies suggested that Asian communication research tended to focus on a certain specific area of communication, such as intercultural communication (Chen, 2006; Kim 2010), international communication (Chitty, 2010), communication technology (Herold \& Seta, 2015; Qiu \& Bu, 2013; Wei, 2009), and political communication (Lo \& Wei, 2010).

So's review (2010) found that telecommunications and political and public opinion were the two most studied topical areas with a total of 136 publications on telecommunications (20.4\%) and 120 articles on political and public opinion (18.1\%). Research on new media and public relations was found to be on the rise. Ha and Pratt (2000) found that journalism studies was the most studied area, and interpersonal communications was the most infrequent topic in published articles concerning communication in Great China.

To explore whether the distribution of research by topic stays narrow or tends to reflect the broad distribution of research in the field, the third research question asked:

RQ3: What were the primary areas of communication research on Asia from 1995 to 2014 ?

Finally, research methods or approaches of inquiry have been viewed as an important indicator of the research trend in past review studies. Lo and Wei (2010) found that the social science research paradigm was dominant in new media and political communication research (totaling 30 articles, $88.2 \%$ ) and only 11.8 percent of publications ( 4 articles in 
total) used critical or interpretive approaches. Li and Tang (2012) examined China-related mass communication research and found different patterns. They collected 159 articles published in 20 major communication journals. They reported that qualitative methods were the more favored methods, accounting for $49 \%$ of the total publications. Quantitative methods, on the other hand, accounted for $42 \%$ of the total. Studies that incorporated both approaches accounted for the remaining $9 \%$. Focusing on methodological choices in communication research on Asia, the fourth research question explored:

RQ4: Which research approaches were used the most in communication research on Asia from 1995 to 2014?

\section{Method}

Based on impact factors (IF) in 2014, a total of 14 top-ranked journalism and communication journals were selected (Communication Research, Journal of Communication, Journal of Health Communication, Public Opinion Quarterly, Journal of Computer Mediated Communication, Human Communication Research, Communication Theory, Communication Monograph, Journal of Broadcasting and Electronic Media, Journalism Studies, Mass Communication \& Society, Journalism and Mass Communication Quarterly, and New Media and Society). Articles published in these journals between 1995 and 2014 containing the keywords Asia countries or Asia/Asian in general in the title and abstract were selected. Accordingly, published articles on Asian immigrants in other non-Asian countries and book reviews were excluded. A total of 558 articles were identified and analyzed.

\section{Coding}

Seven independent coders were trained to code the selected articles published in the 14 journals. Each coder was assigned two journals to code based on their expertise in certain areas. A lead coder was consulted when questions arose. Using Cohen's kappa ( $k$ ) to assess inter-coder reliability, the k ranged from .92 to 1.00 .

\section{Coding schemes}

Research regions and countries. Two variables - research regions and East Asian countries - were used to assess research regions and countries that were studied in the selected publications. The United Nation's list of Asian regions was used to classify the variable of research regions into six categories: (1) South Asia (Afghanistan, Bangladesh, Bhutan, India, Iran, Maldives, Nepal, Pakistan, and Sri Lanka), (2) South East Asia (Cambodia, Laos, Myanmar/Burma, Thailand, Vietnam, Brunei, Malaysia, East Timor, Indonesia, Philippines, and Singapore), (3) East Asia (China, Hong Kong, Macau, Japan, North Korea, South Korea, 
Mongolia, and Taiwan), (4) West Asia/Middle East (Egypt, Syria, Israel, Lebanon, Jordan, Iraq, Saudi Arabia, Kuwait, Bahrain, and Qatar), (5) Central Asia (Uzbekistan, Kazakhstan, Kyrgyzstan, Tajikistan, Turkmenistan), and (6) multiple regions. The variable of East Asian countries/areas was further divided into nine categories: (1) Mainland China, (2) Hong Kong, (3) Macau, (4) Japan, (5) North Korea, (6) South Korea, (7) Mongolia, (8) Taiwan, and (9) multiple countries.

Research topic areas. Research areas by topic were coded by two variables: primary research area and secondary research area. Divisions and interest groups of the International Communication Association (ICA) and the National Communication Association (NCA) were used as the basis for classify topic areas. Accordingly, each variable was coded by 23 categories: (1) advertising, (2) public relations, (3) media effects, (4) political communications, (5) media technology, (6) intercultural communications, (7) mass media, (8) law and policy, (9) health communications, (10) interpersonal communications, (11) organizational communications, (12) media industries, (13) media production, distribution, and promotion, (14) media history, (15) media theory, (16) speech communications, (17) communication psychology, (18) ethics, (19) science communications, (20) journalism, (21) communication research methods, (22) three or more areas, and (23) others.

Methodologies. General methodological approach was coded into five categories: (1) qualitative approach, (2) quantitative approach, (3) critical and interpretative approach, (4) mixed approach, and (5) others.

\section{Results}

\section{The number of publications}

The first RQ explored the trend of published articles concerning Asian communication research over the past 20 years. A total of 558 publications on Asian communication research in the 14 top-ranked communication journals were found in the 20-year period from 1995 to 2014. Over that period, there was a steady increase in the number of publications: from 13 in 1995 to 53 in 2014. This was a 407.69 percent increase (see Figure 1). Thus, the result pointed toward an upward trajectory in Asian communication research over the past 20 years. The years of 2006 (40 articles), 2011 (52 articles) and 2014 (53 articles) marked the peaks of the number of publications on Asia. Incidentally, in these peak years, the following events took place: tsunami in the Indian Ocean, Olympics in Beijing, and the Arab spring protests.

On average, each journal published fewer than two Asia-related articles per year (the average over 20 years was 39.86 articles) (see Table 1, Figure 2). Two publications per year accounted for $5.41 \%$ of their total publications. Among the 14 journals, New Media and Society had the highest percentage of publications on Asia (12.80\%) while Public Opinion Quarterly had the lowest percentage (1.47\%) (see Table 1, Figure 2). 
Article: Trends and patterns in communication research on Asia

\begin{tabular}{lccc}
\hline Journal & $\begin{array}{c}\text { Number of } \\
\text { Articles }\end{array}$ & $\begin{array}{c}\text { Total } \\
\text { Number } \\
\text { of Articles }\end{array}$ & Percentages \\
\hline Communication Research & 46 & 628 & $7.32 \%$ \\
Journal of Communication & 52 & 837 & $6.21 \%$ \\
Journal of Health Communication & 59 & 1301 & $4.53 \%$ \\
Public Opinion Quarterly & 12 & 819 & $1.47 \%$ \\
Journal of Computer Mediated Communication & 54 & 716 & $7.54 \%$ \\
Human Communication Research & 12 & 477 & $2.52 \%$ \\
Communication Theory & 12 & 436 & $2.75 \%$ \\
Communication Monograph & 14 & 463 & $3.02 \%$ \\
Journal of Broadcasting and Electronic Media & 38 & 786 & $4.83 \%$ \\
Journalism Studies & 49 & 786 & $6.23 \%$ \\
Political Communication & 33 & 570 & $5.79 \%$ \\
Mass Communication \& Society & 27 & 468 & $5.77 \%$ \\
Journalism and Mass Communication Quarterly & 48 & 962 & $4.99 \%$ \\
New Media and Society & 102 & 797 & $12.80 \%$ \\
\hline Total & $\mathbf{5 5 8}$ & $\mathbf{1 0 0 4 6}$ & $\mathbf{7 5 . 7 7 \%}$ \\
Average & $\mathbf{3 9 . 8 6}$ & $\mathbf{7 1 7 . 5 7}$ & $\mathbf{5 . 4 1 \%}$ \\
\hline
\end{tabular}

Table 1: The number of published articles on Asia by SSCl journals, 1995-2014

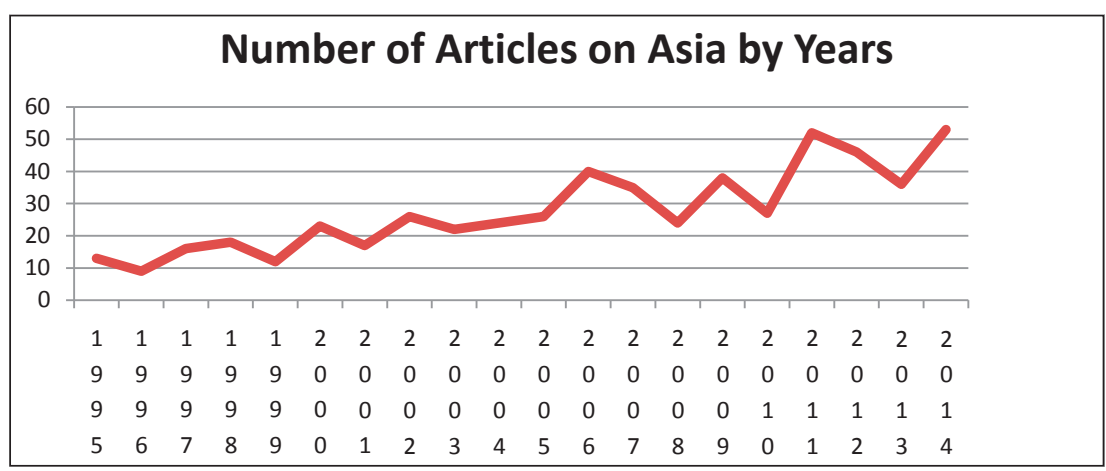

Figure 1: The number of articles on Asia by years from 1995 to 2014

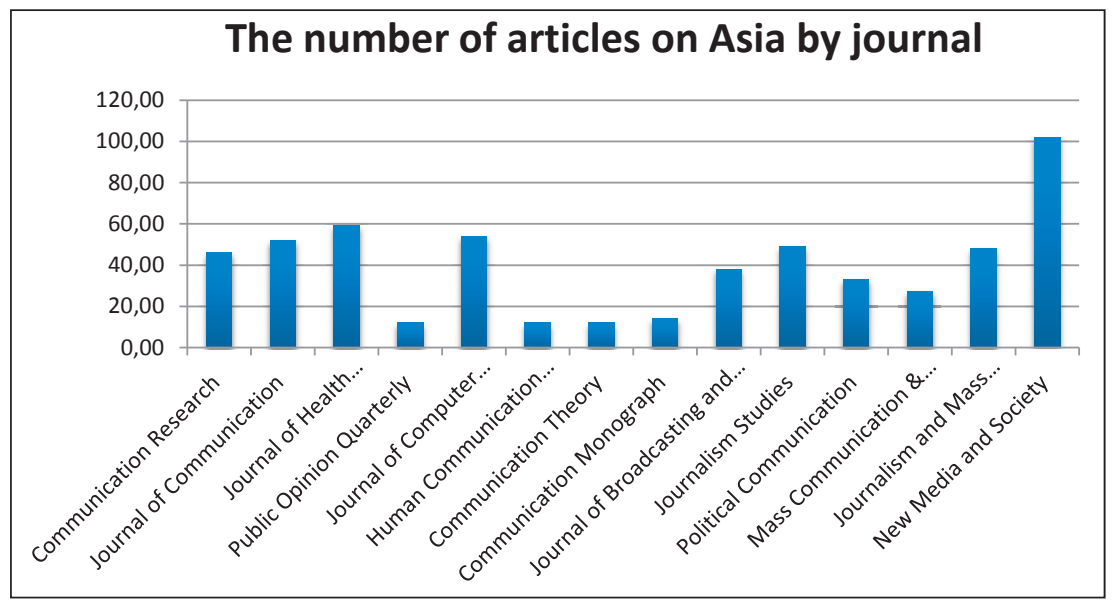

Figure 2: The number of published articles on Asia by SSCI journals, 1995 to 2014 


\section{Publications by region}

RQ2 also explored which region received the most scholarly attention in Asia from 1995 to 2014 and which Asian country(ies) received the most scholarly attention over the past twenty years. In terms of general regions, results showed the dominance of East Asia - in particular, China, South Korea and Japan.

Specifically, there were 280 publications on East Asia (50.18\%), followed by West Asia/ Middle East (16.67\%), South Asia (12.90\%), South East Asia (10.75\%), Central Asia (6.45\%), and multiple Asian regions (2.87\%) (see Table 2). Within the East Asia region, among the 280 publications on East Asia, there were 123 publications on China, followed by South Korea, Japan, multiple regions, Taiwan, Hong Kong, and Macao (see Table 3).

\begin{tabular}{lcc}
\hline Regions & $\begin{array}{c}\text { Number of } \\
\text { articles }\end{array}$ & Percentages \\
\hline South Asia & 72 & $12.90 \%$ \\
South East Asia & 60 & $10.75 \%$ \\
East Asia & 280 & $50.18 \%$ \\
West Asia/Middle East & 93 & $16.67 \%$ \\
Central Asia & 36 & $6.45 \%$ \\
Multiple regions & 16 & $2.87 \%$ \\
\hline Total & $\mathbf{5 5 8}$ & $\mathbf{1 0 0 . 0 0 \%}$ \\
\hline
\end{tabular}

Table 2: The number of published articles on Asia by region, 1995-2014

\begin{tabular}{lcc}
\hline East Asia regions & $\begin{array}{c}\text { Number of } \\
\text { articles }\end{array}$ & Percentages \\
\hline Mainland China & 123 & 38.56 \\
Hong Kong & 24 & 7.52 \\
Japan & 51 & 15.99 \\
Macao & 1 & 0.31 \\
South Korea & 57 & 17.87 \\
Taiwan & 30 & 9.40 \\
Multiple regions & 33 & 10.34 \\
\hline
\end{tabular}

Table 3: The number of published articles on East Asia, 1995-2014

\section{Publications by research topic areas}

RQ3 asked what the primary research areas of communication research on Asia were from 1995 to 2014. The results indicated that the major research areas in Asia communication research were, respectively: media effects (17.20\%), political communication (17.20\%), media technology (13.26\%), health communication (12.19\%), and journalism studies (10.22\%), followed by mass media (6.27\%), others (6.09\%), interpersonal communication 
(3.76\%), media industry (3.41\%), advertising (1.97\%), intercultural communication (1.43\%), media management (1.25\%), and organizational communication (1.08\%). The rest of the research areas (namely, media history, media theory, speech communication, communication psychology, ethics, science communication, public relations, research methods, and law and policy) accounted for less than one percent of all publications on Asia (see Table 4). These results suggested that Asian communication research is diverse in terms of topic areas, reflecting the diversity of the field.

\begin{tabular}{lcc}
\hline Areas & $\begin{array}{c}\text { Number of } \\
\text { Articles }\end{array}$ & Percentages \\
\hline Advertising & 11 & $1.97 \%$ \\
Interpersonal communication & 21 & $3.76 \%$ \\
Organizational communication & 6 & $1.08 \%$ \\
Media industry & 19 & $3.41 \%$ \\
Media management & 7 & $1.25 \%$ \\
Media history & 5 & $0.90 \%$ \\
Media theory & 2 & $0.36 \%$ \\
Speech communication & 1 & $0.18 \%$ \\
Communication psychology & 3 & $0.54 \%$ \\
Ethics & 3 & $0.54 \%$ \\
Science communication & 3 & $0.54 \%$ \\
Public relations & 3 & $0.54 \%$ \\
Journalism & 57 & $10.22 \%$ \\
Research methods & 1 & $0.18 \%$ \\
Media effects & 96 & $17.20 \%$ \\
Political communication & 96 & $17.20 \%$ \\
Media technology & 74 & $13.26 \%$ \\
Intercultural communication & 8 & $1.43 \%$ \\
Mass media & 35 & $6.27 \%$ \\
Law and policy & 5 & $0.90 \%$ \\
Health communication & 68 & $12.19 \%$ \\
Other & 34 & $6.09 \%$ \\
\hline Total & $\mathbf{5 5 8}$ & $\mathbf{1 0 0 . 0 0 \%}$ \\
\hline
\end{tabular}

Table 4: The number of published articles on Asia by research topics, 1995-2014

\section{Publications by research approaches}

RQ4 explored which research approaches were used the most in communication research on Asia from 1995 to 2014. Frequency analysis showed that, among these publications on Asia, more than half of them used a quantitative research approach (58.78\%), followed by qualitative (21.51\%), critical and interpretative (11.83\%), mixed methods (4.84\%), and others (3.05\%) (See Table 5). Therefore, Asian communication research in published articles may be characterized as belonging primarily to the social science paradigm. 
Article: Trends and patterns in communication research on Asia

\begin{tabular}{lcc}
\hline Methods & $\begin{array}{c}\text { Number of } \\
\text { articles }\end{array}$ & Percentages \\
\hline Qualitative & 120 & $21.51 \%$ \\
Quantitative & 328 & $58.78 \%$ \\
Critical and interpretative approaches & 66 & $11.83 \%$ \\
Mixed methods & 27 & $4.84 \%$ \\
Other & 17 & $3.05 \%$ \\
\hline Total & $\mathbf{5 5 8}$ & $\mathbf{1 0 0 . 0 0 \%}$ \\
\hline
\end{tabular}

Table 5: The number of published articles on Asia by research approach, 1995-2014

\section{Discussions}

The present review of communication research on Asia over the 20-year period from 1995 to 2014 indicated that Asia has gained increasing scholarly attention in top SSCl communication journals: increasing from 13 publications in 1995 to 53 publications in 2014. Therefore, the rise of Asian communication research continued in the $21^{\text {st }}$ century.

When the number of published articles was compared across the selected journals, it was clear that newly established journals tended to publish more studies on Asia than journals that have existed for decades. New Media and Society has the highest number of publications on Asia (102 articles), followed by Journal of Health Communication (59 articles), and Journal of Computer Mediated Communication (54 articles). Public Opinion Quarterly, Human Communication, and Communication Theory have the smallest number of publications on Asia (12 articles).

Moreover, journals that focus on communication technology and health communication topics paid more attention to Asia than journals that center on traditional communication areas. This pattern of publication may indicate that research on Asia advances our understanding and knowledge of new disciplines of communication, such as technology and health. However, the presence of Asian communication in the core of communication theories is still limited.

For years, communication researchers have noted the need to develop communication theories and methodologies based on Asian traditions, cultures and communication patterns (Miike, 2009). However, these theories and research activities have not been accepted and published in top-ranked communication journals. Most published research on Asia centers on communication technology and health communication issues. Future studies may explore theoretical and methodological contributions of Asian communication research.

Concerning regions that were researched the most, findings show that more than half of the total publications on Asia (50.18\%) focused on East Asia; and, among countries in East Asia, China was the focus of the largest number of publications (123 article, 38.56\%), followed by South Korea (57 articles, 17.87\%), and Japan (51 articles, 15.99\%). This finding confirmed the unbalanced research across regions and countries in Asia as reported in past studies (Bryant \& Yang, 2004; Kim, 2010). The economic giants of Asia also dominated 
research attention. To find out how the research agenda on Asia has been shaped by geographical factors, future studies may explore what specific topics have been studied in different Asian countries.

In terms of the distribution of research areas by topic, Asian communication scholarship was found to be focused on a few areas, including media effects (17.20\%), political communication (17.20\%), communication technology (13.26\%), health communication (12.19\%), and journalism studies (10.22\%). These five research areas accounted for $70.07 \%$ of all publications on Asia. Other areas, such as media history, media theory, speech communication, research methods and communication ethics, each accounted for less than one percent of Asian communication research. Therefore, the distribution is diverse but uneven.

In terms of research methodologies, the quantitative approach was found to be dominant in publications (58.78\%), which is more than twice the number employing qualitative research (21.51\%) and more than five times the number employing critical and interpretative approaches (11.83\%). These results are consistent with the findings of Lo and Wei on new media and political communication research on Asia. In their sample, the social science research approach was the main approach of inquiry.

In sum, when we examine the whole landscape of communication scholarship on Asia, the results of the analysis suggest patterns of uneven distributions of publications in terms of publishing year, journals, region, research topics and methodology. What accounted for these uneven patterns merits future research.

\section{References}

Bryant, J., \& Yang, M.H. (2004). A blueprint for excellence for the Asian communication research. Asian Communication Research, 1(1), 133-151.

Chen, G.-M., \& Miike, Y. (2006). The ferment and future of communication studies in Asia: Chinese and Japanese perspectives. Retrieved from http://digitalcommons.uri.edu/cgi/viewcontent. cgi?article $=1004 \&$ context $=$ com_facpubs.

Chitty, N. (2010). Mapping Asian international communication. Asian Journal of Communication, 20(2), 181196.

Donner, J. (2008). Research approaches to mobile use in the developing world: A review of the literature. The Information Society, 24(3), 140-159.

Go-global (January 27, 2015). Social media usage in Asia Pacific-Statistics and trends. Retrieved August 20,

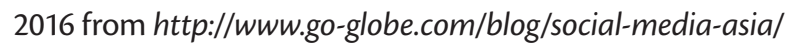

Ha, L., \& Pratt, C. B. (2000), Chinese and non-Chinese scholars' contributions to communication research on Greater China, 1978-98, Asian Journal of Communication, 10(1), 95-114.

Herold, D.K., \& Seta, G. de (2015). Through the looking glass: Twenty years of Chinese Internet research. The Information Society, 31(1), 68-80.

International Monetary Fund. (2016). Regional economic outlook. Asia and Pacific. Washington, D.C. Retrieved August 10, 2016 from http://www.imf.org/external/pubs/ft/reo/2016/apd/eng/areo0516.htm International Telecommunication Union (2016). ICT Facts and Figures 2016. Retrieved August 16, 2016 from http://www.itu.int/en/ITU-D/Statistics/Pages/facts/default.aspx 
Kim, M.S. (2010). Intercultural communication in Asia: current state and future prospects. Asian Journal of Communication, 20(2), 166-180.

Li, S., \& Tang, S. (2012). Mass communication research on China from 2000 to 2010: A meta-analysis. Asian Journal of Communication, 22(4), 405-427.

Lim, S.S., \& Goggin, G. (2014). Mobile communication in Asia: Issues and imperatives. Journal of ComputerMediated Communication, 19(3), 663-666.

Lo, V.H., \& Wei, R. (2010). New media and political communication in Asia: A critical assessment of research on media and politics, 1988-2008. Asian Journal of Communication, 20(2), 264-275.

Lwin, M., \& Salmon, C. (2015) A retrospective overview of health communication studies in Asia from 2000 to 2013. Asian Journal of Communication, 25(1), 1-13.

Miike, Y. (2009). Harmony without uniformity: An Asiacentric worldview and its communicative implications. In Samovar, L.A., Porter, R.E., McDaniel, E.R., \& Roy, C.S. (eds) Intercultural communication: A reader. Cengage Learning. 36-48.

Qiu, J.L., \& Bu, W. (2013). China ICT studies: A review of the field, 1989-2012. China Review, 13(2), 123-152.

So, C.Y. (2010). The rise of Asian communication research: A citation study of SSCI journals. Asian Journal of Communication, 20(2), 230.

Wei, R. (2009). The state of new media technology research in China: A review and critique. Asian Journal of Communication, 19(1), 116-127.

World Bank (April 10, 2016). East Asia Pacific growth remains resilient in face of challenging global environment, says World Bank. Retrieved August 16, 2016 from http://www.worldbank.org/en/news/ press-release/2016/04/10/east-asia-pacific-growth-remains-resilient-in-face-of-challenging-global-environment-says-world-bank.

\author{
Xun ("Sunny") Liu \\ Associate Professor, PhD \\ Department of Communication Studies \\ California State University, Stanislaus \\ sliu@csustan.edu
}

\author{
Ran Wei \\ Professor, PhD \\ School of Journalism and Mass Communications Shanghai Jiao Tong University, China \\ University of South Carolina \\ wei2@sc.edu
}

